Original article (short paper)

\title{
Recording daily routines with guidance on healthy lifestyle to improve health parameters in children and their families
}

\author{
Raiane Maiara dos Santos Pereira \\ Suliane Beatriz Rauber \\ Isabela Almeida Ramos \\ Daniel Tavares de Andrade \\ Universidade Católica de Brasília, DF, Brasil \\ Angeliete Garcez Militão \\ Universidade Federal de Rondônia, RO, Brasil \\ José Fernando Vila Nova de Moraes \\ Universidade Federal do Vale do São Francisco, Petrolina, PE, Brasil \\ Herbert Gustavo Simões \\ Carmen Sílvia Grubert Campbell \\ Universidade Católica de Brasília, DF, Brasil
}

\begin{abstract}
This study investigated the efficacy of using a diary to record daily routines, combined with guidance on healthy lifestyle (GHL) by a physical educator, on promoting changes in health parameters in children. Sixty-three children ( $10 \pm 0.8$ years) were allocated to one of the three following groups: a control group (CON, $n=18)$; a group that did not use the diary, but received GHL $(\mathrm{G}, \mathrm{n}=23$ ); or a group that both used the diary and received GHL (DG, $n$ $=22$ ). Blood pressure, body composition, physical fitness tests (PF), physical activity levels (PAL), and dietary intake profiles were assessed in children and their parents before and after 2 months of intervention. The DG group improved their performance in PF, increased PAL, and reduced body fat $(p<0.05)$. Additionally, $56 \%$ of families from both DG and $\mathrm{G}$ reduced their consumption of unhealthy foods and $70,6 \%$ increased their consumption of healthy foods. Overall, it was concluded that 2 months of using a diary to record daily routines combined with GHL by a physical educator improved PAL, PF, body composition, and dietary intake profiles of children and their families.
\end{abstract}

Keywords: children; diary; health education; healthy lifestyle.

\section{Introduction}

The World Health Organization marks obesity as a major global public health problem ${ }^{1}$. The incidence of overweight and obese children and youth has grown alarmingly over the last decade throughout the world. Overweight and obese children are of concern due to health consequences that may present throughout their lives. Specifically, such children are at an increased risk of developing Type II diabetes, hypertension, dyslipidemia, metabolic syndrome, and bone and joint disorders ${ }^{2-4}$. Further, they are more likely to suffer from psychological disorders, including low self-esteem, higher rates of anxiety disorders, body image disturbance, and depressive symptoms, as well as cognitive deficits that begin in childhood and continue throughout life ${ }^{5-8}$.

According to Adair and cols ${ }^{9}$ this scenario appears to be related more to lifestyle. Considering that the habits acquired during childhood often persist over the course of one's life and that approximately $40 \%$ of obese children become obese adults, effective strategies to promote pediatric health must be a global priority and should be implemented early in life $\mathrm{i}^{10-12}$.

It is clear that improving health habits and lifestyles of children and their families play key roles in preventing obesity ${ }^{4,13}$. However, in order to successfully promote health in childhood, efforts should not only come from families, but also from society in general ${ }^{14-16}$.

Accordingly to Serra-Paya ${ }^{17}$, interventional programs that focus on changing family lifestyles seem to be the most effective strategies to increase physical activity and healthier nutritional choices than traditional interventions (e.g., 10 min consultations with doctors and nurses). Moreover, in order for children to acquire healthy habits, a motivational program that encourages active participation in changing habits must be implemented. However, it has been shown that the participation of parents and health professionals in such programs may be pivotal ${ }^{18}$. Although a selection of researchers have been successful in promoting child health, studies which consider the context of children's lives, such as school and family, in the management of childhood obesity and its long-term effectiveness are still needed. 
In a previous study, it was verified the effectiveness of a lifestyle change program involving children, parents, and teachers through nutrition counseling and promoting physical activity upon health promotion and to prevent obesity in children (2-5 years $)^{19}$. In addition, Poeta ${ }^{20}$ verified that 12 weeks of intervention (nutritional counseling for parents and children) for changing lifestyle in older children (8-11 years) resulted in positive effects in children's health parameters. In a study conducted by our group, it was reported significant improvement in children's (9-11 years) health parameters (anthropometrics, biochemical parameters, physical activity level, and fruit consumption) after attendance in a program supported by a physical educator and parents, which included health guidelines, the use of an educational-motivational tool, and the introduction of recreational activities for ten weeks ${ }^{21}$.

Nevertheless, motivating children to change their lifestyle, continue physical activities, and choose healthier nutritional options daily on their own, remains a significant challenge. Thus, the efficacy of strategies beyond conventional interventions should be tested, either within or outside of the school or care center setting and with a focus on the involvement of both children and parents. Therefore, the present study investigated the efficacy of completing an illustrated, educational, and motivational diary by children, guided by a physical education professional, on improving the lifestyle of children and their families.

\section{Methods}

\section{Participants}

One hundred and twenty-one children enrolled in 4th and 5th grade from a public elementary school at Ceilândia-Distrito Federal-Brazil were invited to participate in the study. The children were allocated into groups according to their scholar grade category (academic year) in order to keep the children in their original group for the health-lifestyle guidance, which occurred once a week. The students participated in one of the following interventional groups as illustrated below (Figure 1). The inclusion criteria consisted of the following: 1 ) age ( 8 to 10 years, the pre-pubertal stage according to the Tanner scale); 2) providing the informed consent signed by the parents; 3 ) the ability to attend the pre- and post-intervention assessments; 4) not having more than two days of absence during intervention days; 5) filling at least $80 \%$ of the educational diary; 6) not having physical or mental limitations that could impair the physical testing achievement; and 7) being able to understand the tasks required. Two children who subsequently withdrew from the study and fifty-six children that did not attend the evaluation days were excluded (Figure 1). Thus, a total of 63 children (27 female and 36 male; $10 \pm 0.8$ years) were eligible to participate in the entire 3-month intervention program. Children were allocated into one of three groups: in a control group that did not use the diary and did not receive guidance on healthy lifestyles (GHL) $(\mathrm{CON} ; \mathrm{n}=18)$; a group that did not use the diary, but received GHL once a week $(\mathrm{G} ; \mathrm{n}=23)$; and a group that both used the diary and received GHL once a week (DG; $\mathrm{n}=22$ ) (Figure 1).

The study was approved by the local ethics committee (protocol 147/2009) and was conducted only after the parents had signed the required informed consent form. The study was conducted between August and September 2012.

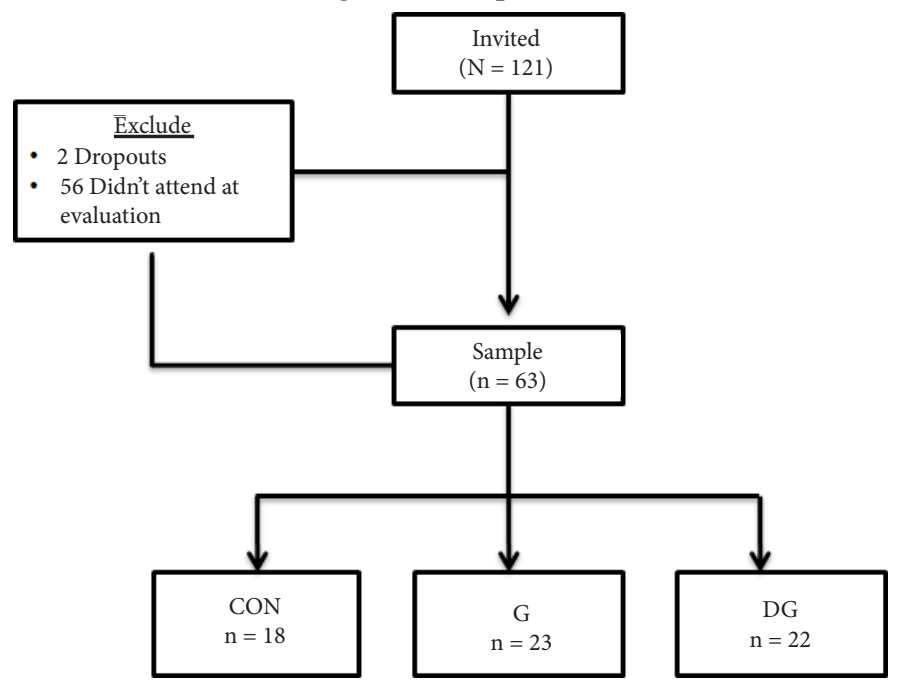

Figure 1. Flowchart of all invited and tested students. CON - control group that did not use the diary and did not receive guidance on healthy lifestyles (GHL); G - group that did not use the diary, but received GHL; DG - group that both used the diary and received GHL.

\section{Procedures}

All data collection was performed on location at the school. In order to complete the study, the children received 23 visits from our research team at school during the 3 months of intervention. Fifteen of these visits ( 1 month) were designated for assessments conducted by a physical education professional who is also an experienced and trained researcher. The assessments were as follows: sexual maturation, anthropometric and body composition, blood pressure, physical fitness tests, and lifestyle questionnaire at pre- and post-intervention. During the remaining visits ( 2 months), children received guidelines detailing how to fill out the diary and how to achieve a healthy lifestyle. These visits lasted one hour once a week for 2 months and were conducted by the same professional. At the end of the intervention, parents answered a questionnaire regarding changes in their child's and their family's lifestyle (nutritional and physical activities) experienced during the participation in the study.

\section{Before and/or After Intervention Assessment}

The Marshall and Tanner board, as adapted by the Brazilian Health Ministry (MS, 2010), was used to assess the sexual maturation of the children before intervention in order to satisfy the inclusion criteria ${ }^{22}$. In addition, the children's physical activity level (PAL) was measured and the Lifestyle Questionnaire (LSQ) proposed by Oliveira ${ }^{23}$ was applied before and after 3 months of intervention. In order to evaluate the effectiveness of intervention on increasing PAL and on improving the nutritional choices on children, a questionnaire was also applied to the children's parents during the third month of intervention. 
The body mass in kilograms (Tanita UM 080W, SP- Brazil,

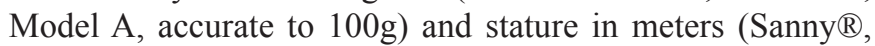
Brazil) were measured and the body mass index (BMI) in $\mathrm{kg} / \mathrm{m}^{2}$ was calculated. Body composition was evaluated by measuring triceps and subscapular skinfolds with a Lange Skinfold Caliper (Maryland, USA) before and after intervention. The prediction equation and procedures according to Guedes \& Guedes ${ }^{24}$ were applied.

Blood pressure (BP) was measured using a sphygmomanometer (Missouri, USA) by the auscultatory method after five minutes of resting in a seated position. The measurement was performed with the child's arm rested at the height of the heart, knees flexed at $90^{\circ}$, and feet touching the ground. The pressure gauge was fit at the child's arm circumference according to Brazilian Society of Hypertension. Five physical fitness tests were performed according to Projeto Esporte Brasil-PROESP (Brazilian Sports Project)25, namely, muscular endurance (sit-ups), flexibility (sit-and-reach), aerobic endurance ( 9 minutes running), lower limb strength (horizontal jump), and upper limb strength (medicine ball throw).

\section{Intervention}

On the first day of intervention, the children were instructed on how to properly fill out the diary. A document explaining how the diary works was also sent to the parents in order to further encourage children to participate in the study.

The diary and the images corresponding to daily activities related to different lifestyles were distributed to the children every week. The diary consisted of one sheet of paper containing a list of the days of the week where the children were instructed to glue the images corresponding to their routine (e.g., what she/he ate and did during each day of the week) (Figure 2). The images were printed on a white sheet of paper and those associated with unhealthy habits (e.g., $\mathrm{TV}$, computer, video games, unhealthy food, high-fat foods, soda, candies, and other unhealthy habits) were in grayscale. While in contrast, images associated with healthy habits (e.g., active playing, sports, water, fruit juice, fruit, vegetables, and other healthy food) were printed in color. The children were encouraged and challenged to change their lifestyle and to turn the diary more colorful throughout the week. The children were instructed to use a "plus (+)" sign to represent the amount of food intake or the time spent performing the activities. Therefore, a sign of "++++" under the TV image glued on the diary paper meant that the child watched TV between 3 and 4 hours; "+++" = 2 to 3 hours; "++" = 1 to 2 hours; and "+" = less than 1 hour.

Figure 2 illustrates an example of what activities one child did in one day: sleeping (6-7 hours); studying seated

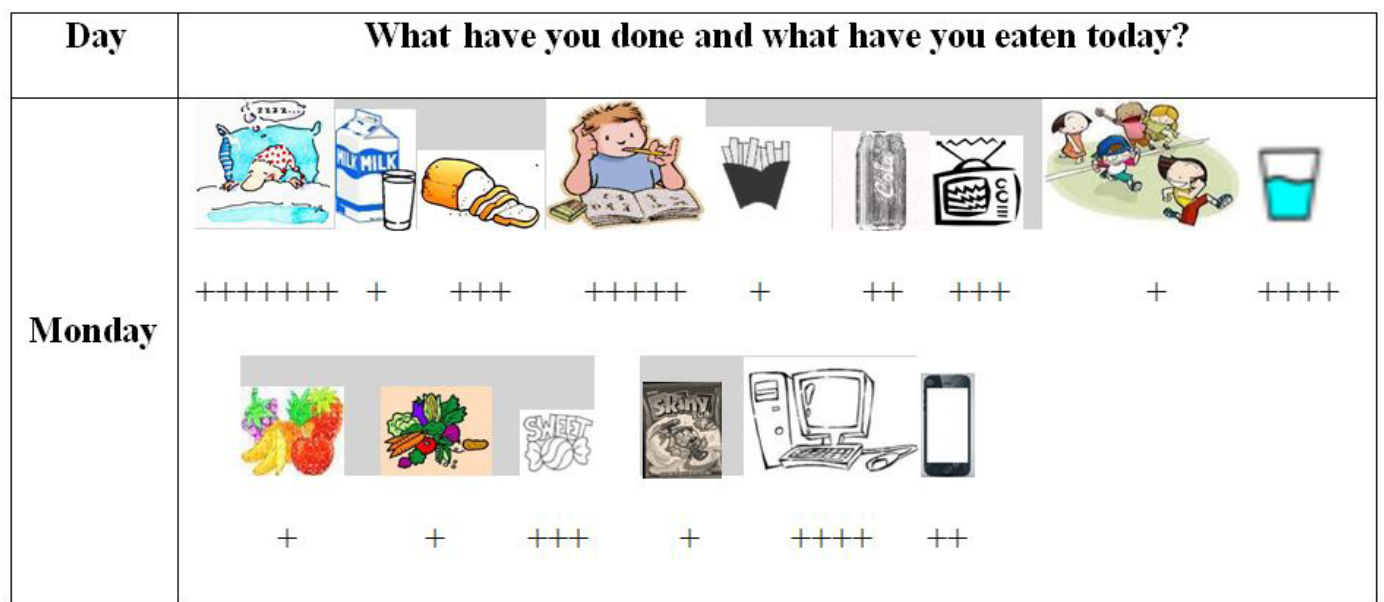

Figure 2. Example of one weekday entry by one child in his diary.

(4-5 hours); watching TV (2-3 hours); playing/running (0-1 hour); computer searching (3-4 hours); and playing on cellphone (1-2 hours). As well as what he/she consumed on the same day: cup of milk (1); bread (3); small French fries portion (1); can of soda (2); cup of water (4); fruit (1); vegetables (1); candies (3); and potato chips (1). If the child performed an activity or ingested a food that was not on the list of images, she/he could draw or write the name of the image in the diary.

From the second week on, the researcher collected the diary from the previous week and handed out a new one to be completed over the following week. Afterwards, with the completed diary from previous week in hand, the researcher guided each child individually about how she/he could improve their daily choices in order to make their next week's diary more colorful and healthier than the week before. A twenty minute dialogue was conducted inside the class by a physical education professional regarding the importance of healthy lifestyle to the experimental groups ( $G$ and DG). Also, forty additional minutes were used to individually guide each child from $\mathrm{G}$ and $\mathrm{DG}$ groups about healthy lifestyles.

\section{Statistical Analysis}

Descriptive analysis was performed and data is shown as mean and standard deviations. Data was analyzed through a 
Split-Plot Analysis of Variance, using Bonferroni's post-hoc to identify the differences between groups (CON, G, and DG) and moments (before and after the intervention). The level of significance adopted was $p<0.05$ and the software used was the SPSS version 18.0 (SPSS Inc., USA).

\section{Results}

The sexual maturation assessment characterized the sample between pre-pubertal and pubertal stages. The boys were classified in stages $1 / 2$ for sexual maturation $(\mathrm{n}=$ $14 / 22)$ and pubic hair $(n=16 / 20)$. The girls were also in stages $1 / 2$ for breasts development $(n=6 / 21)$ and pubic hair $(\mathrm{n}=5 / 22)$. The mean and standard deviation of the analyzed variables are presented in the following figures and tables.

The DG group presented a significant increase $(p=0.02)$ in PAL following intervention (144.3 \pm 47.5 vs $181.1 \pm 55.8)$, going from moderately active to active (Figure 3 ). When comparing PAL between all three groups, a difference between CON and DG groups was observed $(p=0.04)$.

The age, body mass, height, BMI, sum of skinfold thickness, and systolic (SBP) and diastolic (DBP) blood pressure before and after the intervention for each group are presented in Table 1. After the intervention, body mass differed between DG and CON (F $1 / 60=35.89 ; p=0.0001)$, and body fat and lean body mass followed the same pattern $(\mathrm{F} 1 / 60=62.94 ; p=0.0001)$. DBP was significantly higher post-intervention in the CON group when compared to pre-intervention values $(\mathrm{F} 1 / 60=38.05 ; p=0.0001)$.

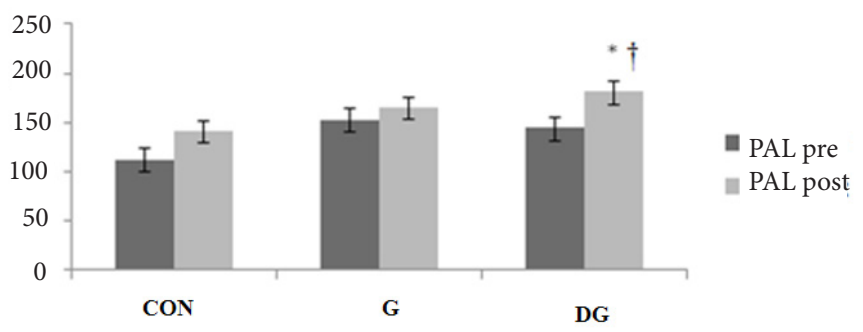

Figure 3. Physical activity levels (PAL) pre- and post-intervention in the group that did not complete the diary or receive guidance on healthy lifestyle $(\mathrm{CON})$; group that did not use the diary but received guidance on healthy lifestyles $(\mathrm{G})$; and the group that both used the diary and received guidance on healthy lifestyles (DG). ${ }^{*} p<0.05$ related to pre-intervention in the same group. $\uparrow \mathrm{p}<0.05$ related to post-intervention in the $\mathrm{CON}$ group.

The results of the physical fitness tests performed pre- and post-intervention are presented in Table 2. The groups G and DG significantly improved their results in three and four physical fitness tests, respectively, when compared to their respective values prior to any intervention. The CON group improved their results only in the medicine ball throw test.

Table 3 shows the changes in the children's lifestyle from $\mathrm{G}$ and $\mathrm{DG}$ groups as reported by their parents during the intervention period.

Table 1. Mean $( \pm \mathrm{SD})$ values of sample characteristics and anthropometric, body composition, and blood pressure data pre- and post-intervention $(\mathrm{n}=63)$.

\begin{tabular}{|c|c|c|c|c|c|c|}
\hline & \multicolumn{2}{|l|}{$\operatorname{CON}(n=18)$} & \multicolumn{2}{|l|}{$G(n=23)$} & \multicolumn{2}{|l|}{ DG $(n=22)$} \\
\hline & Pre & Post & Pre & Post & Pre & Post \\
\hline Age (years) & $9.4 \pm 0.6$ & $9.6 \pm 0.8$ & $10.2 \pm 0.9$ & $10.2 \pm 0.9$ & $10.1 \pm 0.7$ & $10.2 \pm 0.8$ \\
\hline BM (kg) & $32.2 \pm 4.8$ & $32.5 \pm 4.8$ & $33.6 \pm 6.8$ & $34.6 \pm 7.4$ & $37.1 \pm 10.6$ & $38.7 \pm 10.8 \dagger$ \\
\hline $\mathrm{St}(\mathrm{cm})$ & $137.9 \pm 4.9$ & $139.5 \pm 4.7$ & $142.0 \pm 7.8$ & $143.7 \pm 8.4$ & $143.3 \pm 8.4$ & $145.7 \pm 8.8 \dagger$ \\
\hline BMI $\left(\mathrm{kg} / \mathrm{m}^{2}\right)$ & $16.9 \pm 2.2$ & $16.9 \pm 2.6$ & $16.9 \pm 2.6$ & $17.3 \pm 3.0$ & $17.8 \pm 3.7$ & $17.9 \pm 3.4$ \\
\hline$\sum \mathrm{ST}(\mathrm{mm})$ & $23.8 \pm 12.0$ & $25.2 \pm 12.8$ & $24.5 \pm 11.5$ & $21.1 \pm 8.4$ & $26.8 \pm 11.9$ & $24.7 \pm 10.2$ \\
\hline$\% \mathrm{BF}(\%)$ & $24.8 \pm 16.2$ & $25.8 \pm 15.6$ & $22.6 \pm 9.5$ & $20.0 \pm 8.5$ & $27.8 \pm 15.6$ & $25.2 \pm 13.4$ \\
\hline BF (kg) & $8.0 \pm 0.8$ & $8.4 \pm 0.7^{*}$ & $7.6 \pm 0.6 \uparrow \#$ & $6.9 \pm 0.6^{* \dagger \#}$ & $10.3 \pm 1.7 \dagger \#$ & $9.7 \pm 1.4^{*} \uparrow \#$ \\
\hline LBM (kg) & $24.2 \pm 4.0$ & $24.1 \pm 4.1$ & $26.0 \pm 6.2$ & $27.7 \pm 6.8 \dagger \#$ & $26.8 \pm 8.9$ & $29.0 \pm 9.4 \uparrow \#$ \\
\hline $\mathrm{SBP}(\mathrm{mmHg})$ & $110.9 \pm 7.2$ & $115.6 \pm 10.0$ & $118.7 \pm 10.8$ & $114.4 \pm 4.9$ & $116.1 \pm 8.7$ & $114.2 \pm 6.0$ \\
\hline DBP (mmHg) & $62.8 \pm 7.2$ & $73.0 \pm 7.6^{*}$ & $67.6 \pm 7.8$ & $73.65 \pm 9.3$ & $65.6 \pm 7.8$ & $73.9 \pm 8.5$ \\
\hline
\end{tabular}

CON-group that did not use the diary or receive guidance on healthy lifestyle; G-group that did not use the diary but received GHL; DG-group that both completed the diary and received guidance on healthy lifestyles; BM-body mass; St-stature; BMI-body mass index; $\sum$ ST-sum of skinfold thickness; \%BF-percentage of body fat; BF-body fat; LBM-lean body mass; SBP-systolic blood pressure; and DBP-diastolic blood pressure. * $\mathrm{p}<0.05$ related to pre-intervention in the same group; $\# \mathrm{p}<0.05$ related to pre-intervention in $\mathrm{CON} ; \dagger \mathrm{p}<0.05$ related to post-intervention in CON.

Table 2. Mean values $( \pm \mathrm{SD})$ results in the physical fitness tests pre and post intervention $(n=63)$.

\begin{tabular}{lcccccc}
\hline & \multicolumn{2}{c}{ CON $(\mathbf{n}=\mathbf{1 8})$} & \multicolumn{2}{c}{ G $(\mathbf{n}=\mathbf{2 3})$} & \multicolumn{2}{c}{ DG $(\mathbf{n}=\mathbf{2 2})$} \\
\hline SR $(\mathrm{cm})$ & Pre & Post & Pre & Post & Pre & Post \\
SU (rep) & $23.2 \pm 7,5$ & $26.5 \pm 6.1$ & $22.6 \pm 6.9$ & $26.7 \pm 6.0^{*}$ & $23.6 \pm 4.6$ & $27.3 \pm 4.2^{*}$ \\
MT $(\mathrm{cm})$ & $19.0 \pm 13.2$ & $22.6 \pm 9.6$ & $27.7 \pm 6.8$ & $30.0 \pm 8.6$ & $24.8 \pm 7.1 \ddagger$ & $30.8 \pm 7.4 *$ \\
HJ $(\mathrm{cm})$ & $121.4 \pm 21.6 \dagger$ & $124.4 \pm 18.5$ & $139.6 \pm 25.3$ & $149.1 \pm 30.7 * \dagger$ & $133.9 \pm 15.9 \ddagger$ & $139.1 \pm 15.2 \dagger$ \\
9 min R(m) & $1049.8 \pm 150.0$ & $1069.1 \pm 178.8$ & $1090.1 \pm 233.1$ & $1229.7 \pm 153.9^{* \dagger}$ & $1036.6 \pm 159.9$ & $1197.1 \pm 152.1 * \dagger$ \\
\hline
\end{tabular}

SR-sit and reach (flexibility test); SU-sit-ups; MT-medicine ball throw; HJ-horizontal jump; 9 min R-9 min running; CON-group that did not fill the diary neither received guidance on healthy lifestyle; G-group that did not fill the diary but received GHL; DG-group that filled the diary and received GHL. *p $<0.05$ when compared to pre intervention in the same group; $₫ \mathrm{p}<0.05$ when compared to pre-intervention in the G group; $\uparrow \mathrm{p}<0.05$ when compared to post-intervention in the CON group. 
Table 3. Changes in children's lifestyle as reported by their parents.

\begin{tabular}{|c|c|c|}
\hline $\begin{array}{l}\text { Changes in children's lifestyle observed by the } \\
\text { parents after intervention }\end{array}$ & $\begin{array}{l}\text { Yes } \\
(\%)\end{array}$ & $\begin{array}{l}\text { No } \\
(\%)\end{array}$ \\
\hline $\begin{array}{l}\text { Have you observed positive changes in your } \\
\text { child's lifestyle? }\end{array}$ & 71.0 & 29.0 \\
\hline $\begin{array}{l}\text { Have you observed in your child a decrease in } \\
\text { soda consumption? }\end{array}$ & 47.1 & 52.9 \\
\hline $\begin{array}{l}\text { Have you observed in your child a decrease in the } \\
\text { ingestion of candy? }\end{array}$ & 41.2 & 58.8 \\
\hline $\begin{array}{l}\text { Have you observed that your child's food dish has } \\
\text { been more colored and contains healthier foods? }\end{array}$ & 64.7 & 35.3 \\
\hline $\begin{array}{l}\text { Have you observed that your child spends more } \\
\text { time in active play? }\end{array}$ & 82.4 & 17.6 \\
\hline $\begin{array}{l}\text { Have you observed if your child asks you to take } \\
\text { him to the park more often? }\end{array}$ & 47.1 & 52.9 \\
\hline $\begin{array}{l}\text { Have you observed if your child asks you to take } \\
\text { him to clubs for leisure more often? }\end{array}$ & 52.9 & 47.1 \\
\hline $\begin{array}{l}\text { Have you observed if your child is more motivated } \\
\text { to perform physical activities? }\end{array}$ & 76.5 & 23.5 \\
\hline \multicolumn{3}{|l|}{ Changes in family lifestyle after intervention } \\
\hline $\begin{array}{l}\text { Did you observe if someone in the family started to } \\
\text { play a sport, physical exercise or physical activity? }\end{array}$ & 25.4 & 74.6 \\
\hline $\begin{array}{l}\text { Did you observe a decrease in the consumption } \\
\text { of corn or potato chips, mayonnaise, hot dogs and } \\
\text { french fries in the family? }\end{array}$ & 58.8 & 41.2 \\
\hline $\begin{array}{l}\text { Did you observe a decrease in the consumption of } \\
\text { soda, ice cream, and candy by the family in general? }\end{array}$ & 52.9 & 47.1 \\
\hline $\begin{array}{l}\text { Did you observe an increase in the ingestion of } \\
\text { fruit and vegetables by the family? }\end{array}$ & 70.6 & 29.4 \\
\hline $\begin{array}{l}\text { Do you believe that filling out the diary was a } \\
\text { positive contribution to improving your child's } \\
\text { and family's lifestyle? }\end{array}$ & 100.0 & 0.0 \\
\hline
\end{tabular}

\section{Discussion}

The present study investigated the efficacy of using an illustrated and educational diary by children, guided by a physical education professional, on improving healthy lifestyle in children and their families. Results showed that only 2 months of recording daily routines in a diary in combination with guidance on healthy lifestyle by a physical education professional promoted positive changes, both in families' daily nutritional choices and in children's physical activity levels, physical fitness, and body composition. Differently from $\mathrm{G}$ and CON, the DG group increased in the intensity, duration, and level of physical activity, as demonstrated by the answers in the LSQ before and after intervention. The results from the questionnaire showed that the children from the DG group upgraded their activity levels from moderately active to active. However, no significant difference was found when comparing PAL between DG and G groups.

The guidance on healthy lifestyles conducted once a week for 2 months positively influenced the children to become more active, which was confirmed by the parent's answers to the questionnaire. These findings should be considered when defining public policies regarding health promotion and disease prevention, beginning at school. As a suggestion, theoretical classes of "physical activity and healthy nutrition" or "physical exercise, nutrition, and health" would be offered together with traditional physical education practices for promoting healthy lifestyle for children.

When comparing PAL between all three groups, there was a significant difference between CON and DG but not between $\mathrm{CON}$ and $\mathrm{G}$. This suggests that using such a motivational tool, by filling out a diary of lifestyle choices associated with a co-participative intervention of a physical education professor, helped the children to increase their PAL in comparison to those that only received guidance on healthy lifestyles. In agreement with the present study, Mello, Luft and Meyer $^{26}$, who aimed to compare two strategies of managing childhood obesity verified that the group that only visited the ambulatory once a month (height and weight measurement, received information about how to control their diet, and were encouraged to perform physical activity) was less effective in overcoming sedentary behavior compared to the group who underwent an educational program (classes, homework, lessons about healthy habits, planning goals, and free activities). The education and awareness of children, parents, and teachers about healthy lifestyle can be powerful tools for health promotion and disease prevention in childhood. However, in some cases, the intervention program targeted to parents and children must be demanding in order to be successful, as proposed by Natale ${ }^{19}$. These authors verified positive changes in lifestyle in children ( $2-5$ years) in care centers for low-income families which attended an educational program with nutrition counseling and promotion of physical activity involving the children, their parents, and teachers. The intervention group had to follow strict "policy," in which water became the primary beverage for staff and children, the cow's milk provided contained only $1 \%$ fat, and juice was limited to once a week. In addition, daily snacks and meals incorporated fresh fruits and/or vegetables, physical activity was encouraged to reach 60 minutes per day, and TV/video game/computer viewing was logged and limited to only 30 minutes/week. However, this program was performed in younger children, which has a higher probability of being successful than one for older children who may need motivational strategies to change and maintain a healthy lifestyle.

Filling a diary of daily routine added to guidance on healthy lifestyle during 2 months resulted in a change in the lifestyle of the older kids ( $8-10$ years) and their families as reported by the parents. These changes resulted in improvement of the level of physical activity, body composition and physical fitness verified on these children. However for how long these changes could be sustained needs to be investigated. Similar to our results, Poeta ${ }^{20}$ verified the effectiveness of nutritional counseling for parents and children in combination with physical activity promotion (3 times per week) in older children (8-11 years). The authors observed a significant decrease in body fat, BMI, skinfold thickness, arm circumference, and increased hand grip strength and physical fitness levels after 3 months of intervention. However, these authors included physical activities during the intervention, while in our study, the children were encouraged to practice physical activities of their choosing on their own time. 
In our study, 2 months of intervention promoted improvement in body composition and physical fitness, which ultimately reduces cardiovascular risk in these children. Body fat percentages significantly decreased for the DG and G groups following the intervention, while for the CON group, they increased. The BMI was maintained due to the increase in body mass and stature concomitantly, which was expected for children of this age group.

The intervention also resulted in improvement of physical fitness. Both DG and G improved their results in four (sit and reach, sit-ups, medicine ball throw, and 9 minutes running) and three tests (sit and reach, horizontal jump, and 9 minutes running), respectively, while $\mathrm{CON}$ only performed better in the upper limb strength test (medicine ball throw). Monitoring these physical fitness variables during childhood contributes to the prevention of the development of chronic-degenerative diseases, such as stroke, cancer, cardiovascular diseases, diabetes, hypertension, and osteoporosis ${ }^{27,28}$. These physical fitness results suggests that 2 months of recording their daily routines in a diary and receiving guidance on healthy lifestyle helped children to improve their flexibility, aerobic conditioning, muscular strength, and endurance. On the other hand, both CON and DG group increased their medicine ball throw distance $(p<0.05)$, however, their improvements were $11 \%$ and $18 \%(p=0.02)$, respectively. In addition, the mean distance of the medicine ball throw after the intervention was significantly higher in $\mathrm{G}$ when compared to $\mathrm{CON}(p=0.03)$. This supports that weekly guidance on healthy lifestyles and/or using a diary contributed to the increases in upper limb strength of these children.

We should also consider that the positive results obtained in this study could be greater if physical activity had been introduced in addition to a longer intervention period.

In particular, Militão ${ }^{21}$ used a similar educational tool (diary + guidance on healthy lifestyle by one physical educator) and introduced $2 \mathrm{~h} /$ week of recreational activities for 3 months in children (9-11 years) with their parents' support. After 3 months of intervention, significant improvement in most of the health parameters evaluated was observed as follows: decrease in waist circumference, BMI, body fat percentage, systolic blood pressure, LDL cholesterol, total cholesterol, triglycerides, and intake of candy and sweetened drinks; while significant increases in the consumption of fruits and PAL were observed.

The use of this simple intervention over a two-month period in our study resulted in many health benefits for the children and may play a role in promoting children's health. For example, diastolic blood pressure was significantly higher post-intervention in the CON group. It is known that physical activity and physical fitness are inversely related to blood pressure (BP) values in children and that improvement in physical fitness is associated with a reduction in cardiovascular risk factors in children ${ }^{29}$. Hence, we can suggest that the improvement of physical fitness and nutritional pattern for both $\mathrm{G}$ and DG groups in our study would protect them from blood pressure elevation and cardiovascular risk factors.

Elizondo-Montemayor et al. ${ }^{30}$, in a study with 10 months of dietary and physical activity intervention in 96 overweight/ obese Mexican children aged 6-12 years, reported significant decreases in the prevalence of metabolic syndrome and its associated factors, including blood pressure, BMI percentile, and body fat percentage. It is important to underline that the benefits of physical activity for children are not only long-term, but also acute $^{31}$. Indeed, this previous study verified lower blood pressure and lower cardiovascular reactivity to stress after 30 minutes of traditional outside play (tag, dodgeball, and flag football $)^{31}$. These results show the potential role of playing strategies in or outside school for cardiovascular health in childhood.

Concerning nutrition, the present study revealed an increase in the consumption of fruits and vegetables, and a decrease in the intake of soft drinks and unhealthy foods after barely 2 months of intervention. Consequently, the use of this educational tool in addition to guidance on healthy lifestyle not only helped the children to introduce healthier foods to their diet, but also to reduce the consumption of unhealthy foods, as well as motivated them to increase their physical activity level and fitness. The interesting fact was that the physical activity was only encouraged and not explicitly provided by the intervention. Therefore, we can suggest that the application of this tool was effective to achieve our goals.

A school-based intervention can reduce the prevalence of overweight and obesity in children and may affect eating habits at home ${ }^{32}$. Specifically, they recorded a decrease in the prevalence of overweight and obesity by $3.2 \%$ and $14.0 \%$, respectively, after an intervention in which eating healthy food and being physically active was encouraged in five schools. Similarly, it was observed a significant decrease in the consumption of french fries and potato chips after 3 months of physical activity program in children attending the $3^{\text {rd }}$ and $4^{\text {th }}$ grades. However, no statistical differences were observed regarding physical activity levels ${ }^{33}$.

Indeed, educational intervention programs in school coupled with a commitment from parents for children's health promotion have great potential to succeed. Children usually follow the habits of their parents, meaning that if their mother or father is obese, they are more prone to be overweight or obese too. ${ }^{34}$ Accordingly, it was observed that the effect of parental BMI on children's BMI may have both a genetic and an environmental link. Children determine their behavior by associating with their parent's behavior ${ }^{35,36}$. However, in the present study, changes in the families' lifestyles could be observed in the questionnaire answered by the parents. The participation of the children in the intervention was shown to contribute to changes in the family's daily routine; $25.4 \%$ referred to initiating sports activities, $70.6 \%$ increased their consumption of fruit and vegetables and 50-60\% reduced their amount of unhealthy food consumption. Finally, all parents $(100 \%)$ answered that using the diary had a positive contribution to the improvement of their child's lifestyle. So, clearly, the intervention utilized in this study applied by a physical education professional during only 2 months resulted not only in the improvement of children's health parameters, but also in the motivation to adopt a healthy lifestyle for both the children and their families.

\section{Study Limitations and Strengths}

Limitations of the present study included the use of subjective methods to measure dietary habits and indirect methods to 
evaluate PAL. Therefore, the extent in which the recorded dietary habits and PAL reflect actual habits may be questioned. Also, some groups had different assessment results in the pre-intervention period, but this aspect could not be controlled. The dynamics of the school did not allow researchers to move children to a group different from their original group of students. Also, a group that only used the diary was not included, which would potentially provide some additional interesting results. Thus, it is not possible to know how much this educational tool, if applied alone, could influence the participants' lifestyle. Finally, the efficacy of using a diary in a longitudinal design must be investigated.

\section{Conclusion}

The use of an illustrated educational diary with daily routines in addition to guidelines about healthy lifestyles from a physical education professional once a week for 2 months resulted in improvement in health parameters, physical fitness, and physical activity levels in children. Moreover, it also contributed to changes in the diet and daily lifestyle of children and their families.

\section{References}

1. World Health Organization 2010. Available from: http://www. who.int/whosis/whostat/2010/en/ (accessed on June 30, 2014).

2. Carletti L, Rodrigues AN, Perez AJ, Vassallo DV. Blood pressure response to physical exertion in adolescents: influence of overweight and obesity. Arq Bras Cardiol. 2008; 91(1): 24-30.

3. Obarzanek E, Wu CO, Cutler JA, Kavey RE, Pearson GD, Daniels SR. Prevalence and incidence of hypertension in adolescent girls. J Pediatr. 2010; 157(3): 461-467, 467.e461-465.

4. Michels N, Susi K, Marques-Vidal PM, Nydegger A, Puder JJ. Psychosocial Quality-of-Life, Lifestyle and Adiposity: A Longitudinal Study in Pre-schoolers (Ballabeina Study). Int J Behav Med. 2016; 23:383-392.

5. Yanovski JA. Pediatric obesity. An introduction. Appetite. 2015; 93:3-12.

6. Verdejo-García A, Pérez-Expósito M, Schmidt-Río-Valle J, Fernández-Serrano M J, Cruz F, Pérez-García M, Campoy C. Selective alterations within executive functions in adolescents with excess weight. Obesity (Silver Spring). 2010; 18(8): 1572-1578.

7. Kamijo K, Pontifex MB, Khan NA, Raine LB, Scudder MR, Drollette ES, Hillman $\mathrm{CH}$. The negative association of childhood obesity to cognitive control of action monitoring. Cereb Cortex. 2014; 24(3):654-662.

8. Davidson TL, Boutelle KN. Special issue of Appetite: The proceedings of the American University Symposium on Childhood Obesity and Cognition. Appetite. 2015; 93:1-2.

9. Adair LS, Gordon-Larsen P, Du SF, Zhang B, Popkin BM. The emergence of cardiometabolic disease risk in Chinese children and adults: consequences of changes in diet, physical activity and obesity. Obes Rev. 2014; 15( Suppl 1): 49-59.

10. Tammelin T. Lack of physical activity and excessive sitting: health hazards for young people? J Pediatr. 2009; (Rio J) 85(4): 283-285.
11. Freedman DS, Khan LK, Serdula MK, Dietz WH, Srinivasan SR, Berenson GS. Inter-relationships among childhood BMI, childhood height, and adult obesity: the Bogalusa Heart Study. Int J Obes Relat Metab Disord. 2004; 28(1): 10-16.

12. Waters E, de Silva-Sanigorski A, Hall BJ, Brown T, Campbell $\mathrm{KJ}$, Gao Y, Summerbell CD. Interventions for preventing obesity in children. Cochrane Database Syst Rev. 2011; (12): CD001871.

13. Avis JL, Jackman A, Jetha MM, Ambler KA, Krug C, Sivakumar M, Ball G.D. Lifestyle Behaviors of Parents of Children in Pediatric Weight Management: Are They Meeting Recommendations? Clin Pediatr (Phila).2015; 54:1068-1075.

14. Dobbins M, Husson H, DeCorby K, LaRocca RL. School-based physical activity programs for promoting physical activity and fitness in children and adolescents aged 6 to 18 . Cochrane Database Syst Rev. 2013; 2: CD007651.

15. Mikkelsen MV, Husby S, Skov LR, Perez-Cueto FJ. A systematic review of types of healthy eating interventions in preschools. Nutr J.2014; 13(1): 56.

16. Mendonça G, Cheng LA, Mélo EN, de Farias Júnior JC. Physical activity and social support in adolescents: a systematic review. Health Educ Res. 2014

17. Serra-Paya N, Ensenyat A, Real J, Castro-Viñuales I, Zapata A, Galindo G, Teixidó C. Evaluation of a family intervention programme for the treatment of overweight and obese children (Nereu Programme): a randomized clinical trial study protocol. BMC Public Health. 2013;13:1000.

18. Hedegaard M, Fleer M. Play, Learning, and Children's Development: Everyday Life in Families and Transition to School. Cambridge University Press. 2013.

19. Natale RA, Messiah SE, Asfour L, Uhlhorn SB, Delamater A, Arheart KL. Role modeling as an early childhood obesity prevention strategy: effect of parents and teachers on preschool children's healthy lifestyle habits. J Dev Behav Pediatr. 2014; 35(6): 378-387.

20. Poeta LS, Duarte MS, Caramelli B, Jorge Mota, Giuliano IC \& Back. Efeitos do exercício físico e da orientação nutricional no perfil de risco cardiovascular de crianças obesas. Revista da Associação Médica Brasileira. 2013; 59(1): 56-63.

21. Militão AG, de Oliveira Karnikowski MG, da Silva FR, Garcez Militão ES, Pereira RMS, Campbell CSG. Effects of a recreational physical activity and healthy habits orientation program, using an illustrated diary, on the cardiovascular risk profile of overweight and obese schoolchildren: a pilot study in a public school in Brasilia, Federal District, Brazil. Diabetes Metab Syndr Obes. 2013; 6: 445-451.

22. Marshall WA, Tanner JM. Variations in the pattern of pubertal changes in boys. Arch Dis Child. 1970; 45(239): 13-23.

23. Oliveira LS de. Atividade física e hábitos alimentares em adolescentes com excesso de peso [dissertação]. Brasília: Universidade Católica de - UNB; 2009.

24. Guedes DP, Guedes JE. Controle e Peso Corporal. Composição Corporal Atividade Física e Nutrição. Paraná, Midiograf, 1998.

25. Silva D, Pelegrini A, Petroski EL, Gaya ACA. Comparação do crescimento de crianças e adolescentes brasileiros com curvas de referência para crescimento físico: dados do Projeto Esporte Brasil. Jornal de Pediatria. 2010; 86(2):115-120. 
26. Mello ED, Luft VC, Meyer F. Atendimento ambulatorial individualizado versusprograma de educação em grupo: qual oferece mais mudança de hábitos alimentares e de atividade física em crianças obesas? Jornal de Pediatria. 2004; 80(6): 468-474.

27. Braam KI, vdTP, Takken T, Veening MA, van Dulmen-den Broeder E, Kaspers GJ. Physical exercise training interventions for children and young adults during and after treatment for childhood cancer. Cochrane Database Syst Rev. 2013; 4: CD008796.

28. Vasconcellos F, Seabra A, Katzmarzyk PT, Kraemer-Aguiar LG, Bouskela E, Farinatti P. Physical Activity in Overweight and Obese Adolescents: Systematic Review of the Effects on Physical Fitness Components and Cardiovascular Risk Factors. Sports Med. 2014; 44:1139-1152.

29. Gonçalves R, Szmuchrowski LA, Damasceno VO, de Medeiros ML, Couto BP, Lamounier JA. Association of body mass index and aerobic physical fitness with cardiovascular risk factors in children. Rev Paul Pediatr. 2014; 32(3): 208-214.

30. Elizondo-Montemayor L, Gutierrez NG, Moreno DM, Martínez U, Tamargo D, Treviño M. School-based individualized lifestyle intervention decreases obesity and the metabolic syndrome in Mexican children. J Hum Nutr Diet. 2013; (26 Suppl 1):82-89.

31. Rauber SB, Boullosa DA, Carvalho FO, de Moraes JF, de Sousa IR, Simões HG, et al. Traditional games resulted in post-exercise hypotension and a lower cardiovascular response to the cold pressor test in healthy children. Front Physiol. 2014; 5:235.

32. Marcus C, Nyberg G, Nordenfelt A, Karpmyr M, Kowalski J, Ekelund U. A 4-year, cluster-randomized, controlled childhood obesity prevention study: STOPP. Int J Obes (Lond). 2009; 33(4): 408-417.

33. Herbert PC, Lohrmann DK, Seo DC, Stright AD, Kolbe LJ. Effectiveness of the energize elementary school program to improve diet and exercise. J School Health. 2013; 83(11): 780-786.

34. Morgan PJ, Collins CE, Plotnikoff RC, Callister R, Burrows T, Fletcher R, et al. The 'Healthy Dads, Healthy Kids' community randomized controlled trial: a community-based healthy lifestyle program for fathers and their children. Prev Med. 2014; 61: 90-99.
35. Steffen LM, Dai S, Fulton JE, Labarthe DR. Overweight in children and adolescents associated with TV viewing and parental weight: Project HeartBeat! Am J Prev Med. 2009; 37(1 Suppl): S50-S55.

36. Gubbels JS, Kremers SP, Stafleu A, de Vries SI, Goldbohm RA, Dagnelie PC, et al. Association between parenting practices and children's dietary intake, activity behavior and development of body mass index: the KOALA Birth Cohort Study. Int J Behav Nutr Phys Act. 2011; 8:18.

\section{Acknowledgements}

The authors would like to thank to the Coordenação de Aperfeiçoamento de Pessoal de Nível Superior (CAPES) and Conselho Nacional de Desenvolvimento Científico e Tecnológico (CNPq) for the financial support to the study, as well as for granting the scholarships in graduation and undergraduate research level (CNPq), MSc (CAPES), and for school, children/parents participants in this study.

\section{Corresponding author}

Suliane Beatriz Rauber

Laboratory Studies in Physical Education and Health

Catholic University of Brasilia - Campus I - QS 07 Lote 01 EPCT, Águas Claras, Taguatinga, DF, Brazil

Email: suliane.edfisica@gmail.com

Manuscript received on August 02, 2015

Manuscript accepted on February 25, 2016

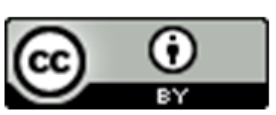

Motriz. The Journal of Physical Education. UNESP. Rio Claro, SP, Brazil - eISSN: 1980-6574 - under a license Creative Commons - Version 3.0 